\title{
Job satisfaction and intention to quit: an empirical analysis of nurses in Kuwait
}

\section{* Dr.Hamadah W.M}

\begin{abstract}
The aim of this study was to identify the facets influencing job satisfaction and intention to quit of nurses employed in Kuwait. . The purpose of the study was to assess the degree of the job satisfaction, and level of intention to change jobs of these groups. Two hypotheses were formulated. Dissatisfaction with the job nature, income and social prestige of nurses would result in intentional of withdrawing from nursing and - or the nursing profession and dissatisfaction with the supervisor, patient, colleague, promotional opportunity, education an training, workload and shift duty would elicit intention of leaving the present working sector. The variable of intention to quit was adopted here to stand for nurses job commitment. A result, a more practical and long term plan could be recommended to improve the future retention and recruitment of nurses in Kuwait.

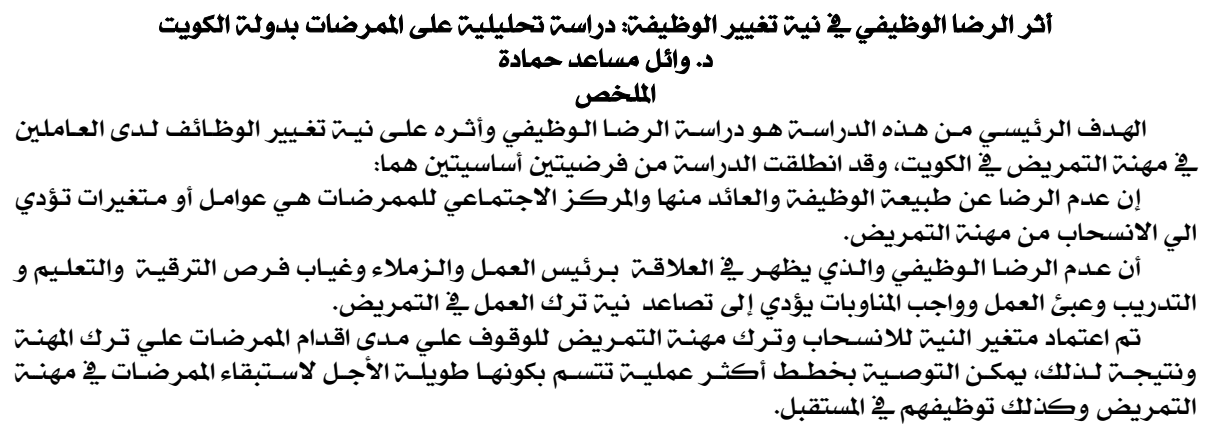

\section{Introduction}

"If there is one system that holds the potential to reverse the trend of growth and speed up the decline in nation's fortunes, it's health system" (M.A. Al-Bustan, 87). There has been tremendous development in Kuwait's health care delivery system since 1980 . Till 1989, the progress was linear-the number of hospitals increased from 11 to 16 and the number of Primary Health Care Clinics, from 53 to 68 . The various facilities within the latter showed expansion. For example, the number of dental
\end{abstract}

Director of Nursing Institute

The Public Authority for Applied Education \& Training - Kuwait 
clinics went up from 94 in 1980 to 222 in 1989; maternal care centers 18 to 24 ; childcare centers from 28 to 43 and preventive care centers, from 23 to 30 . The number of beds increased by 14 percent; physicians by 39 percent dentists, by 87 percent; nurses by 24 percent; and pharmacists by 43 percent. (AL-Ansari \&AL-Enezi, 17)

The linear progress was seen till 1989 suffered from a setback due to Iraqi aggression which led to a collapse in all infrastructure aspects of health care. The number of clinics, hospital beds, doctors, dentists, nurses, and pharmacists - all showed a significant decrease as compared to 1989 levels. This phenomenon isn't very surprising, as the year 1991 was the year of great upheavals. The country was under occupation until February 1991 and devoid of most its inhabitants. After the liberation, and for quite sometimes afterwards, the population balance did not reach the 1989 (or pre-invasion) level

( http://www.kuwait-info.com/sidepages/health_over.asp)

People both natives and expatriates tricked back to the liberated country. The signs of recovery became visible. The figures for later years once again showed the same momentum set in motion in the early 1980s. However, in recent years a downward trend has been recorded in some health care indicators.

Nowadays, the Ministry of Public Health provides almost $90 \%$ of the health services. It has six general hospitals and sixteen specialty hospitals and clinics providing tertiary-level care, with a total of 9,139 hospital beds, 105 clinics providing primary-level care, and 30 dental clinics. In addition, the Ministry of Education has more than 600 school clinics. The Ministry of Public Health has a total of 65,338 employees (medical doctors, nurses, and other professional and technical staff).( State of Kuwait. Ministry of Information, 2017)

Comparison of the 3 last decades reveals a decrease in the number of physicians per thousand populations. Simultaneous increase in population per doctor. There are indications that the national policy of gradual kuwaitization in the public services is bearing fruit. The percentage of Kuwaiti physicians and dentist in Kuwait's health care system (both government and private) increased. Respectively, on the other hand the percentage of Kuwaiti nurses decreased. 
Nowadays, the health service system is undergoing a stage of assessment and review especially following the period of fast expansion coupled with administrative progress on a high level of efficiency and knowledge.

With a view of implementing the future health plan and disseminating the health awareness on the largest scale possible, the Ministry of Public Health had divided Kuwait into six health zones: Farwaniya - Jahra - Adan Mubarak Al-Kabeer - Amiri and Shuwaikh. Each of the previous serve about 300 thousand and 500 thousand person.

The Ministry had followed in this division the style of modern health management, following the basis of non-centralization in management, and updated the health emerging system, and supplying health institutions with all its requirements of specialized physicians and modern equipment; each health zone has its own responsible manager enjoying full administrative authorities. (Health Systems Profile- Kuwait,13)

The health system in every zone is based on a public hospital, health center and health units including clinics and specialized clinic: if the patient needs a special treatment he is referred to Sabah public center which includes a number of hospitals and specialized centers. Gynecology - Psychiatry - Chest diseases - Specialized Surgeries Oncology - Fevers Physical Medicine and Rehabilitation - Chest Diseases and protection from Tuberculosis - Cancer - Sensitivity - Kidney - Dermatology - Inheritance Ophthalmology - Dentistry - Treatment with Chinese Pins and medical Herbal. The policy of establishing the medical zones aims at making the health services more handy and available to citizens as well as to make the medicine available to them, and to make them take part in the responsibility of determining health problems in the zone and studying such problems to find the best solutions therefore. (Health Systems Profile- Kuwait, 14)

Among the basic objectives that the Ministry of Health seeks to realize are the improvement of medical efficiency, the recruitment of more Kuwaiti specialists and the reduction of dependence on foreign manpower. In order to achieve those objectives, a Faculty of Medicine was established in 1973 and a Faculty of Allied Health Sciences and Nursing within Kuwait University in 1982. Both colleges enjoy a distinguished 
reputation for supplying the Ministry of Health with the specialized staff needed. Besides, the Nursing Institute founded in 1962, and Kuwait Medical Specialties Institute, established in 1987, helps raise the technical standard of fresh graduates and provide them with advanced training in various fields. (Health Systems Profile- Kuwait, 19)

To boost the technical standard of physicians and qualifying those with training emerged the idea of establishing the Institute of Nursing in 1962 and Kuwait Institute for medical specialization in 1984. In 2000, Kuwait had five government general hospital- one in each health region plus the specialized Sabah Medical Center (include the Sabah General Hospital); 9 specialized hospitals; and 23 diabetes clinics. A total of 28,278 individuals worked in the Ministry of health, in 2000. Of these, 44.5 percent were males and 55.5 percent females, 49 percent Kuwaitis and 51 percent NonKuwaitis. Female workers outnumbered the males among both nationality groups, in general. A total of 8232 nurses worked for the Ministry of Health in 2000 only 12 percent of them, Kuwaitis. The proportion of male and female nurses was approximately 1:5. Doctors, nurses, and dentists constituted approximately 42 percent of the total work force in the Ministry of health (11\%, $29 \%$ and $1.8 \%$ respectively). The rest (58\%) was comprised of pharmacists, paramedical technicians, administrators, and others.

During such changes, the morale and job satisfaction of health care professionals naturally warrants the community's attention. The morale and job satisfaction of the health care professionals needed to be high, so that the implementation of changes could be carried out smoothly. Specifically, the nursing profession was the most direct contacts with patients; and yet it also suffered a serious shortage of manpower (Hakeem et al, 1999). In turn the workload of nurses increased. Thus nurse's job satisfaction was an important issue for academics, administrators and policy makers in health care system.

Although the Ministry of Health has worked out and implemented a series of recruitment and retention strategies, it could not be denied that Kuwait is still facing the problem of a critical shortage of nurses. The shortage of nurses not only affects the implementation of the changes but also influences the day-to-day running of health care services. ." 
Shortage of the manpower in health sector is considered one of the major problems affecting the quality of health services, specially in developing countries" (A. Al-Awadhi, 1987).

In Kuwait, hundreds of staff nurses leave nursing every year. A total of $9 \%$ governmental nurses left the services in the 10 month of 2007, compared to $10 \%$ 2003; and 7\% in 2000; and 6\% in 1999(Department of Statistics \& Medical Records Health \& Vital Statistics Division 2001)

Although the tendency of an increasing turnover rate has slackened, the figure still remains at a high level of about $10 \%$ at present.

Nursing job satisfaction and turnover has long been a concern for many years in many countries. However, there remains a serious problem in the conduct of research on the job satisfaction and turnover of nurses in Kuwait. Nowadays, there is a critical imbalance in turnover and recruitment of nurses in Kuwait, and the condition needs to be addressed as the high turnover rate which will have its impact on the quality of patient care. (Applebaum et al., 2010)

To reduce nurse turnover rates require understanding of the factors contributing to it. However, these factors seem to be poorly understood (Cavanagh, 1998). There appeared to be no linear relationship between any of the factors and the decision to leave. Price and Mueller (1995) suggested that job satisfaction was an intermediary variable influencing the intention to stay, which in turn affected turnover. In order to discover the factors contributing to high turnover rate of nurses in Kuwait, Job satisfaction among nurse needs to be studied since understanding of nurse's job satisfaction is important for the purpose of recruitment and retention of nurses (Ma'soumah A. Ibrahim \& Ghanem Sulten, 1999).

Job satisfaction had long been studied in nursing as a predictor of turnover of nursing staff and quality of patient care rendered. In order to interpret the turnover of nurses, the relationship between job satisfaction and intention to change job of nurse's needs to be understood. In this study, a descriptive survey design was used to investigate the relationship of job satisfaction and the intention to change jobs among Nurses in Kuwait.

This study is a descriptive survey and data were collected through an English self-administered questionnaire that was modified from the 
"Nurse's job Satisfaction Measure". The sample was selected by nonprobability sampling method. After sampling, the development of instrument is illustrated. The dependent and independent variables are defined after the identification of hypotheses. In order to establish the validity of the instrument, a pilot study is carried out.

After data collection, the data were processed through the data processing flows. Univariate Data Analysis, Bivariate Data Analysis, and multivariate Data Analysis then analyzed them. The results were presented both descriptive and graphically. An in-depth discussion of the results was made. Prior to the conclusion of the is paper, the limitation and recommendation were identified.

\section{LITERATURE REVIEW}

In this section, we briefly describe the factors of job satisfaction, job dissatisfaction and intention to quit of nurses from the present workplace. Some keywords are examined including nurses, nursing, job dissatisfaction, job satisfaction, intention to quit, turnover intention.

Job satisfaction is defined as the emotional feelings as well as the behavioral expression for a job. The feeling is influenced by some job related factors such as pay, different types of benefits, recognition, working condition, relation with coworker and supervisors, and others (Cowin et al., 2008). Similar to other professions, it is acknowledged that nurses' job satisfaction is inversely linked with their intention to quit their profession (Applebaum et al., 2010)

Nurse's satisfaction and retention have been important issues for Minster of Public Health in Kuwait. After all, high levels of quitting and staff turnover can affect your bottom line, as temps, recruitment and retraining take their toll. But few practices (in fact, few organizations) have made job satisfaction a top priority, perhaps because they have failed to understand the significant opportunity that lies in front of them. Satisfied employees tend to be more productive, creative and committed to their employers. Recent studies have shown a direct correlation between staff satisfaction and patient satisfaction. Family nurses who can create work environments that attract, motivate and retain hard-working individuals will be better positioned to succeed in a competitive health care environment that demands quality and cost-efficiency. What's more, 
nurses may discover positive workplace for their employees, they've increased a positive workplace for their employees, and they've increased their own job satisfaction as well. (Cowin et al., 2008).

Job satisfaction is defined as the emotional feelings as well as the behavioral expression for a job. The feeling is influenced by some job related factors such as pay, different types of benefits, recognition, working condition, relation with coworker and supervisors, and others (Cowin et al., 2008; Yılmazel, 2013).

Similar to other professions, it is acknowledged that nurses' job satisfaction is inversely linked with their intention to quit their profession (Applebaum et al., 2010). Researchers discovered that highly satisfied nurses do not quit the existing job (Flinkman et al., 2008). A review on nurses' job satisfaction expressed that job satisfaction of nurses is positively associated with job stress, depression, and organizational commitment (Lu et al., 2012). In addition, they identified that job satisfaction had a moderate relationship with some determinants e.g., role ambiguity, recognition, supervisor support, and coworker cooperation. They found a weak association with nurses' personal characteristics for example, gender, age, years of experience, education level, and dealing with strategies. They also revealed an inconsistent impact on job satisfaction for same determinants across nations. For instance, job satisfaction was strongly correlated with individual characteristics (e.g., age) among US nurses (Çimen \& Şahin, 2000; Kavanaugh, Duffy \& Lilly, 2006), but no correlation was found among nurses in China (Lu, While \& Louise Barriball, 2007). Van B ogaert et al. (2010) reported that job stress was positively associated with job satisfaction among nurses in Belgium though no relationship was found among nurses in USA (Packard \& Motowidlo, 1987).

Employee retention and turnover are the most objective measures of employee satisfaction / dissatisfaction in organizations. Many companies and organizations feel that employee compensation is the dominant factor in employee satisfaction. Consequently, employers attempt to " buy" employee satisfaction with increased pay and benefits. In today competitive business environment this approach can only be taken so far. Fortunately, there is much less expensive way to create greater employee 
satisfaction. It is virtually cost free and it increases productivity, which significantly improves the bottom line. ( (Han \& Jekel, 2011).)

Studies on nurses' job satisfaction in different countries revealed that job satisfaction is usually moderate or low in nursing profession (Akgöz et al., 2005; Asegid, Belachew \& Yimam, 2014; Sabanciogullari \& Dogan, 2015; Yilmazel, 2013). Sizeable research is reported on nurses' job satisfaction and job dissatisfaction in various settings. For example, a survey on job satisfaction of 98,110 nurses from nine countries conducted by Aiken et al. (2011) reported that job satisfaction was peak in Germany (83\%) followed by USA (78\%), New Zealand and Canada (67\%), South Korea (64\%), UK (63\%), China (54\%), and Japan (40\%). Researchers argued that the levels of nurses' job satisfaction may vary across samples and countries. They also stated that similar factors may not affect the level of job satisfaction in different countries (Zhu et al., 2012). In Greece, a study on cardiac certified clinical nurses revealed that $38 \%$ of nurses were unhappy with their supervisors and $34 \%$ with their colleagues (Iliopoulou $\&$ While, 2010). They also reported that $34 \%$ of them were satisfied with their hospital management, and $81 \%$ nurses expressed payment/salary as a significant job satisfaction dimension. In addition, researchers explored some factors that lead to job dissatisfaction. These are low public appreciation for nursing profession or poor image of the profession, low wages, inadequate social opportunities, poor relationship with the management, lack of job security, inadequate involvement in decisionmaking processes, and inflexible working hours (Aiken et al., 2013; ElJardali et al., 2009). Other developing countries such as public health services in Malaysia indicated that the major contributors include heavy workload, repetitive work, and poor working environment. Respondents identified that inconsiderate and inequitable superior/matron, lack of recognition, and conflict within and between groups were common factors of satisfaction facets (Loo \& Beh, 2012).

Currently, turnover issue among the nurses is one of the prime concerns in the healthcare sector. Keeping this in mind, researchers explored some significant factors that prompt nurses' decision retention or to quit their profession. 
Applebaum et al. (2010) asserted that turnover intention of nurses is positively associated with nursing workload, stress for work, and burnout. Similarly, Meeusen et al. (2011) stated that emotional and psychological fitness of nurses deteriorated because of excessive workload and lack of coworker and supervisor support. Consequently, turnover intention is increased.

A survey on job satisfaction of healthcare professionals and their intention to quit the job reported that length of professional experience is an important factor for nurses' job satisfaction and their intention to quit from the profession (Kavanaugh, Duffy \& Lilly, 2006).

In addition, they found that individual characteristics (e.g., gender, age educational level, and race) are not liable for variances in job satisfaction. Recent studies indicate that nurse turnover or their intention to quit is associated with transformational leadership style (Raup, 2008) and participative governance in hospital (Gormley, 2011). Furthermore, Leiter, Price \& Spence Laschinger (2010) and Delobelle et al. (2011) described that nurses are inspired for their turnover intention more by managers/supervisors than by coworkers.

A myriad of research shows that demographic characteristics are associated with nurses' turnover intention. In recent works, researchers discovered an inverse relationship between turnover intention and individual's age in nursing profession (Chan et al., 2009; Ma et al., 2009).

It is observed that nurses in Ireland reported a greater tendency of premature retirement because of being female, kinship responsibilities, high workload, and lack of training opportunities in the workplace (McCarthy, Tyrrell \& Lehane, 2007). Moreover, Delobelle et al. (2011) found that the turnover intention of nurses is inversely related with years of nursing experience in South Africa while in Jordan, job satisfaction of nurses is positively correlated with years of nursing experience and their age (Mrayyan, 2005). Similarly, Chan et al. (2009) reported that fresh graduates are highly interested to quit the current position within their first year of nursing practice. However, Beecroft, Dorey \& Wenten (2008) argued that fresh graduate nurses feel committed to the organization, and turnover intention is lower given that they are happier with their professions and pay. Some 
recent works show that turnover intention of nurses is positively associated with higher levels of nursing education (Delobelle et al., 2011; Stewart et al., 2011). Besides, Chan et al. (2009) revealed that educational level of nurses is strongly correlated with their turnover intention or intention to stay in the organization. They reported that the higher level of education, the higher level of turnover in current position.

On the contrary, Borkowski et al. (2007) stated that greater professional commitment in nursing is correlated with higher education of nursing (e.g., bachelor/master degree/PhD.). They also expressed that a highly educated nurse bears lower intention to quit the profession.

In a contemporary study, Meeusen et al. (2011) reported that lack of fairness, politics, threats to personal safety, and the risk of possible layoffs are causes of increased job dissatisfaction among nurses.

In a recent study, researchers explored that job satisfaction has a moderate relationship with supervisor support, coworker support and recognition in nursing (Lu et al., 2012). Also, they reported that pay, fringe benefits, and contingent rewards are associated with nurses' job satisfaction, and these factors are highly related with turnover intention. Some researches show that pay and financial benefits are considered as the most significant factors for job satisfaction among male nurses compared to that of female nurses (Borkowski et al., 2007; Chan et al., 2009). In addition, Leiter, Price \& Spence Laschinger (2010) stated that intention to quit the nursing profession is associated with the support of nursing staff and manager's ability. In the same way, Tourangeau \& Cranley (2006) concluded that nurses are more likely to continue work in current position who perceived their team members as cohesive and supportive.

William M. Mercer, Inc. found in surveying 206 medium to large companies in 1998 that in organizations with high turnover, compensation was the most common reason given for dissatisfaction. However, in companies with very low turnover, $40 \%$ of the respondents perceived emotional factors (work satisfaction, good relationships with managers and other employees) as completely motivating their retention as compared to $21 \%$ attributing financial factors. Compensation and benefits satisfy the two lowest needs of Maslow's hierarchy, while the 
emotional factors satisfy the three upper needs of the Hierarchy. (Kacel, Miller \& Norris, 2005; Mrayyan, 2005).

A work environment that constantly raises an employee's self- esteem, will yields very high employee satisfaction with their job and costs next to nothing. A Principle" people do more of what they enjoy and less of what they don't enjoy! ". Consequently, people who enjoy working are more productive. ( Heinen et al. (2013)

In the late 1950s, Frederick Herzberg, considered by many to be a pioneer in motivation theory interviewed a group of employees to find out what made them satisfied and dissatisfied on the job. He asked the employees essentially two sets of questions: Think of a time when you felt especially good about your job. Why did you feel that way? Think of a time when you felt especially bad about your job. Why did you feel that way? ( J. Michael Syptak,1999)

From these interviews Herzberg went on to develop his theory that there are two dimensions to job satisfaction: Motivation and Hygiene. Hygiene issues, according to Herzberg, cannot motivate employees but can minimize dissatisfaction, if handled probably. In other words, they can only dissatisfy if they are absent or mishandled. Hygiene topics include company policies, supervision, salary, interpersonal relations and working conditions. They are issues related to the employee's environment. Motivators, on the other hand, create satisfaction by fulfilling individuals' needs for meaning and personal growth. They are issues such as achievement, recognition, the work itself, responsibility and advancement. Once the hygiene areas are addressed, said Herzberg, the motivators will promote job satisfaction and encourage production. ( J. Michael Syptak,1999)

Although hygiene issues are not the source of satisfaction, these issues must be dealt with first to create an environment in which employee satisfaction and motivation are even possible.

Company, administrative policies and organization's policies can be a great source of frustration for employees if the policies are unclear or unnecessary or if not everyone is required to follow them. Although employees will never feel a great sense of motivation or satisfaction due 
to your policies, you can decrease dissatisfaction in this area by making sure your policies are fair and apply equally to all.

To decrease dissatisfaction in this area, you must begin by making wise decisions when you appoint someone to the role of supervisor. Be aware that good employees do not always make good supervisors. Salary is the old adage" you get what you pay for" tends to be true when it comes to staff members. Salary is not a motivator for employees, but they do want to be paid fairly. If individuals believe they are not compensated well, they will be unhappy working for you. Interpersonal relations which is a part of satisfaction of being employed is the social contact that brings, so allow employees a reasonable amount of time for socialization (e.g., over lunch, during breaks, between patients). This will help them develop a sense of camaraderie and teamwork. At the same time, you should crack down on rudeness, inappropriate behavior and offensive comments. If an individual continues to be disruptive, take charge of the situation, perhaps by dismissing him or her from the practice. (Flinkman et al., 2008).

Working conditions is the environment in which people work has a tremendous effect on their level of pride for themselves and for the work they are doing. We can't neglect hygiene factors because employees would be generally unhappy, and this would be apparent to your patients. Second, your hardworking employees, who can find jobs elsewhere, would leave, while your hardworking employees, who can find jobs elsewhere, would leave, while your mediocre employees would stay and compromise your practice's success. So deal with hygiene issues first, then move on the motivators. (Flinkman et al., 2008).

Work itself perhaps most important to employee motivation is helping individuals believe that the work they are doing is important that their tasks are meaningful. Emphasize that their contributions to the practice result in positive outcomes and good health care for patients. Share stories of success about how an employee's actions made a real difference in the life of a patient, or in making a process better. Make a big deal out of meaningful tasks that may have become ordinary, such as new-baby visits. Of course employees may not find all their tasks interesting or rewarding, but you should show the employee those tasks are essential to the overall processes that make the practice succeed. You 
may find certain tasks that are truly unnecessary and can be eliminated or streamlined, resulting in greater efficiency and satisfaction. (Lu et al., 2012).

Achievement one premise inherent in Herzberg's theory is that most individuals sincerely want to do a good job. To help them make sure you've placed them in positions that use their talents and are not set up for failure. Set clear, achievable goals and standards for each position, and make sure employees know what those goals and standards are. Individuals should also receive regular, timely feedback on how they are doing and should feel they are being adequately challenged in their jobs. Be careful, however, not to overload individuals with challenges that are too difficult or impossible, as that can be paralyzing.

Recognition individuals at all levels of the organization want to be recognized for their achievements on the job. Their successes don't have to be monumental before they deserve recognition, but your praise should be sincere. If you notice employees doing something well, take the time to acknowledge their good work immediately.

The relationship between environment and individual's wellbeing were illustrated in the Person-Environment-Fit Theory. Caplan (1984) related job satisfaction to ' goodness of fit ' between the needs and abilities of individual, and the opportunities and demands of the environment. 'Needs supply fit' explain how the needs and values of the individual fir with supplies and opportunities which existed in a particular environment. 'Abilities demand fit' looked at the demands of the environment and the abilities of the individual to meet these demands.

Stamps and Piedmont (1986) proposed the Social-Reference-Group Theory to describe job satisfaction by connecting with group influence. Job satisfaction was a function of the characteristics of the job that met the desires of the groups. Additionally, a worker looked for Guidance in evaluating his or reality. Nevertheless, the satisfaction of the individual was based on the satisfaction of peer group. The group might desire certain job factors, then, if an individual could get those particular factors in his work, the individual would be more satisfied with the job.

They argued job satisfaction from different perspectives. There was little consensus on how to define and measure the components of job 
satisfaction. It appeared that no single theory completely explains the phenomenon, but that all of them described important concepts and relationships related to job satisfaction. So the majority of theorists appeared to agree that job satisfaction was multifaceted and somehow related to the ability of the job, or its environment, to meet unique, individual's human needs.

The most obvious methods for a manager to improve unite staffing is to decrease turnover of nursing personnel. Annual nursing turnover is the percentage of employed nurses who are separated from their jobs during a year's time. Annual turnover rates of nursing personnel are usually higher than for women employees in other industries (Institute of Medicine, 1993; Prine and Muller, 1991).

At regular intervals, the attitudes of current employees should be surveyed to identify sources of job satisfaction or dissatisfaction. An attitude survey of registered and practical nurses in a university hospital revealed that turnover could be predicted by "leavers" and "stayers" different responses to selected survey items. In general, "leavers" reported lower overall job satisfaction, lower satisfaction with supervision, lower satisfaction with opportunities to use personal abilities, and increased feeling of tension and pressure." Stayers " were generally older, had more seniority in the agency, and were better job performers than "Leavers". Researchers concluded that nurse's principle motivation for resignation from the studied hospital was frustration of employee's needs for growth and development (Seybolt et al., 1978).

If correlation studies have identified personal, educational, or experiential qualifications that correlate with satisfaction in a particular position, job requirements should be rewritten to include those qualifications, so as to ensure the selection of the best-qualified candidate for each job.

In a study of new graduate staff nurses, the most significant cause for dissatisfaction was assignment of too much responsibility too soon, with the result that the neophyte felt overwhelmed by the supervisor's expectations for her or his clinical performance Cronin-Stubbs, (1977). A survey of register nurses in medical surgical unites of several acute care hospitals revealed a significant correlation between perceived work 
overload and intent to resign jolma, (1990). This research concluded that registered nurse turnover could be decreased if nonprofessional duties now performed by registered nurses were assigned to personnel with less education and training. This expert and others advise that the primary nursing concept be refined to allow for a "nurse extender" or "practice partner" role. A nurse extender is a practical nurse, a nurse aide, a respiratory therapist, an electrocardiograph technician or technician of another type, who paired with an RN who serves as primary nurse for a caseload of patient.

One study of employee motivation revealed that job satisfaction is related to different factors for groups with different educational backgrounds. For ancillary nursing personnel, job satisfaction resulted from the feeling of being a member of the "hospital team." For technical nursing personnel, job satisfaction resulted from being viewed as " skilled professionals" and having the opportunity to acquire new skills. For professional nursing personal job satisfaction resulted from a supportive interpersonal environment and the opportunity to shape agency policies Carey et al., (1997).

Nursing home nursing assistants were surveyed in the northwest to determine whether the assistants' turnover rates were related to satisfaction of survival, security, belonging, esteem, and self-actualization needs Maslow, (1970). Finding revealed the following relationships among need satisfaction and job turnover for studied nursing assistants. Employees who received the highest pay and spent least for food and shelter (survival needs); who felt they were a valued member of their work group, felt "needed" by their patients, and had a head nurse who "listened" to their concerns (security and belonging needs) had longest job tenure. Those who ranked themselves highest in nursing skills (selfesteem) had the longest job tenure.

A survey of nurses in four acute care hospitals in a Southeastern metropolitan area revealed that nurse managers' leadership style was significantly correlated with staff nurses' job satisfaction (Lukas, 1991). Staff nurses in this study reported a preference for the consulted style of management which is characterized by considerable confidence in subordinates' abilities, both downward and upward communication, 
motivation through rewards, involvement, and occasional punishment, moderate delegation of responsibility to subordinates, and consultation with subordinates about management decisions (Likert and Likert 1976).

Job satisfaction is defined as one's affective response to the job. However, studies show that an individual's job is not a unitary attitude object. Instead, job satisfaction has several dimensions. According to Locke (1976), the following are job dimensions about which workers develop attitudes on a like-dislike continuum: nature of the work; pay; promotion opportunity; recognition; working conditions; benefits; supervision; coworkers; and clients. According to "Locke", a worker's rating of any dimension as very positive or very negative indicates that the dimension is important enough to provoke string feelings. Conversely, neutral feelings of satisfaction about a specific job dimension means that the dimension has little significance for worker's total job satisfaction.

Some believe that job satisfaction reflects a degree of congruity between a worker's expectations of the job and experience of the job Locke, (1976) Vroom, (1964) White and Mitchell (1979) claim that the degree of job satisfaction is influenced by a worker's perceptions of the other workers' satisfaction in the same job. Herzberg (1966) claims that a worker's job satisfaction results from a different set of factors from those that cause job dissatisfaction. According to Herzberg, job satisfaction depends on the amount of autonomy, responsibility, recognition, and achievement afforded by the job; and dissatisfaction is associated with work environment and conditions. On the other hand, Katz and Van Maanen (1977) claim that job satisfaction derives from distinct factors: job properties (similar to Herzberg's satisfies); interactional context for work (one of Herzberg's environment factors); and work policies (another Herzberg's environment factors).

Several studies revealed that nurses experience low levels of job satisfaction. In a study of several types of health care personnel, the lowest job satisfaction was reported by hospital staff nurses Hurka, (1974). Survey of nurses in Chicago and San Francisco McClosky, (1974) revealed that psychological rewards, such as educational opportunities, career advancement systems, peer recognition, and research opportunity, and "safety" rewards, such as salary increase, extended 
vacation, and such as salary increase, extended vacation, and improve work schedules, produced greater job satisfaction than did social rewards, such as socializing with peers and sharing opinions and feelings.

In a study by Moser and Kerkorian (1999), hospice nurses found interaction with clients and family a greater source of job satisfaction than working conditions. In a study by Thiry (1998), nurses reported their greatest job satisfaction from pleasant superior-subordinates relationships and their greatest dissatisfaction from inadequate job information and ineffective conflict handing.

In a survey of Florida nurses Ginsberg et al. (2000), one-third of respondents reported substantial job dissatisfaction, and one-half reported dissatisfaction with the nursing career. For this nurse, the major reasons for job dissatisfaction were inadequate salary, devaluation of nursing work, and difficult duty hours. In a survey of Texas nurses (Wendell et al., 1981), the primary causes of job dissatisfaction for employed nurses were inadequate salaries, excessive paperwork, lack of administrative support, and lack of in-service education. Unemployed nurses reported difficult work schedules and unsatisfactory relations with physicians as reasons for leaving nursing. In small-group interviews, nurses reported job dissatisfaction from work overload, need to assist other personnel, and need to "float" to other nursing units. In a study of New York nurses hunter et al., (1986) unionized nurses reported dissatisfaction with salary, bonus policy, and compensation for education and experience; but satisfaction with grievance procedures and fringe benefits. Nonunionized nurses reported dissatisfaction with grievance procedures, fringe benefits and compensation for education, but satisfaction with salary.

Many studies have shown that rates of nursing staff turnover are often too high, "hospital nurses having more than three times the turnover rate of teachers and more than one-and-a-half times the turnover rate of social workers." In an American Health Care Association RN Manpower Survey, $82 \%$ of nursing homes responding needed more nurse aides, $76 \%$ were short of licensed practical nurses (LPNs) and 71\% reported a shortage of RNs. The American Nurses' Association 1991 survey estimated 
the vacancy rate for nursing homes at $19 \%$, compared to $13 \%$ for home health care agencies.

Rates of turnover in different studies tend to vary. Turnover rates fluctuate according to type of facility, administration, location and characteristics of the current workforce, but also result from varying assessment methods. Some studies include only voluntary separations, while others include all types of separations. Anticipated turnover, rather than actual turnover, has been the subject of investigation in several studies. Also, in recent years, researchers have begun to assess not only when workers leave, but who is leaving, where they are going and why.

Models of turnover Israel in the literature usually are causal and multistaged. They begin with job and/or personal factors as the initial cause(s) and consider satisfaction/dissatisfaction as a mediating factor. Other variables tend to vary with the model. Several models add mobility or opportunity to leave as a predictive variable; some add intention to leave/stay as an intervening variable between job satisfaction and actual turnover. Some emphasize within-person expectations, attitudes and responses, while others include "objective" characteristics of the person and/or the environment. Concern over job satisfaction of employees in business and industries have increased in the past few decades.

Cathy and Constancy (1998) found in their study that autonomy, cohesion, and fairness are positively related to job satisfaction, while pressure is negatively related to job satisfaction. Neither sales manager's perceptions of recognition or innovation are related to job satisfaction.

Employees who are satisfied and happy with their jobs are less likely to be absent from work, regardless of their mood states. Those employees who reported high negative moods and who were satisfied with their jobs were absent significantly less often than those in the same negative mood and who were not satisfied. When Employee view work as pleasurable experience they come to work even they wake up in a depressed mood. (Leiter, Price \& Spence Laschinger, 2010)

To conclude, concern over job satisfaction of employees in the health care field has increased in the past few decades. Job satisfaction is defined as the pleasurable or positive emotional sate resulting from the appraisal of one's job or job experience, and there are many theories explaining the 
concept of job satisfaction. These include Two-Factor Theory, NeedFulfillment Theory, Person-environment-Fit Theory, and Social-ReferenceGroup Theory. The turnover models can be used to evaluate the specific propositions about the relationships between variables in job satisfaction.

In the literature, there is a commonly assumption that individual's dissatisfaction with their current work role is the major cause of turnover; therefor the relationship between job satisfaction and turnover was examined. Some studies reported that there was a significant relation between job satisfaction and turnover, e.g., hunter et al., (1986) while some did not.

\section{PURPOSE OF THE PRESENT STUDY}

According to these findings from the previous literature, the purpose of the present study is to discuss the relationship between job satisfaction and intention to change jobs among nurses in State of Kuwait.

Assess the degree of the job satisfaction, level of intention to change jobs of these groups. Two hypotheses were formulated. Dissatisfaction with the job nature, income and social prestige of nurses would result in intentional of withdrawing from nursing and - or the nursing profession and dissatisfaction with the supervisor, patient, colleague, promotional opportunity, education training, workload and shift duty would elicit intention of leaving the present working sector.

The variable of intention to quit was adopted here to stand for nurse's job commitment. A result, a more practical and long term plan could be recommended to improve the future retention and recruitment of nurses in Kuwait.

The aims of this study were designed to address the following questions:

1. How satisfied were nurses with their jobs?

2. Do Nurses want to change jobs?

3. What is the intention of nurses in changing job: move to other health care sectors or leaving the nursing professional?

4. Does nurse's job dissatisfaction cause intention of quitting?

\section{METHODOLOGY}

After decades of research in organization psychology, organization behavior and human resources management, relationships among some job-related variables (e.g. job satisfaction and turnover) has been 
discovered and conclusions thereon mad in other countries. Furthermore, many instruments have been developed to measure the job satisfaction.

However, the reliability and validity of these instruments might be questionable (Cornelia M Roland, 2007) when they were used in the Egypt community as the culture, society climate, norms and values of nurses might be different. The nurses in Kuwait were growing synapse of eastern and western culture. They were educated within British Education system and Canadian system and American system. But their norms and values were deeply influenced by Arabic culture.

This introduced difficulties concerning conclusion of causal relationships in the analysis of result. The institutional and cultural differences of many result. The institutional and cultural differences of various societies and the special characteristics of particular professions needed to be considered. Hole (1996) noted that cross-cultural and crosssetting measures of job satisfaction are intrinsically invalid and unreliable. Therefore, deviation of results might be predicted if the instruments were adopted as the measuring tools. Obviously, a locally developed instrument tool was more preferable.

\section{Research Design}

The design of the study was descriptive, and the study used survey approach to explore the -phenomena of concern. Data collected through an English self-administered questionnaire that was modified from the instrument by Kwong M (1995). The questionnaire was distributed to 3 Medical areas in Kuwait, which are Farwaniya -Adan - Shuwaikh, and returned anonymously and on a voluntary basis.

\section{Sampling Procedure:}

The study subjects were the nurses in Kuwait. The population under study included the full-time nurses, which are working in the Ministry of Public Health in three medical areas in Kuwait. In the first stage of sampling, 3 Medical areas had been chosen out of 6 Medical areas. Ministry of Public Health had divided Kuwait into six health zones, being Farwaniya - Jahra -Adan - Mubarak Al-Kabeer -Amiri - Shuwaikh, each of which serves about 300 thousand and 500 thousand person. 3 Medical areas were randomly selected from 6 medial areas. Then 104 Nurses were randomly chosen from the medical area. 
It was difficult to obtain a complete list of Nurses from hospital authority, therefor; a convenience sampling method has been adopt in selecting the samples. After the hospitals are selected, four wards from each hospital are selected randomly. The questionnaires, with a covering letter explaining the conditions of the voluntary participation and confidentiality of the contained data, were then distributed to all the nursing confidentiality of the contained data, were then distributed to all the nursing staff of the selected wards. A total of 311 Nurses were recruited into this study. Distribution and collection of the questionnaire was completed between February and April.2019

\section{Development of Instrument}

The instrument developed to measure the impact of job satisfaction on the turnover was a structured questionnaire was modified from the questionnaire which was developed by Kwong $M$, (1995). Some alterations were made and several variables have been made and several variables have been added to the questionnaire.

The instrument consisted of demographic data and 38 items, which were measured on a five-point Likert scale and forced optional of strongly, disagree, disagree; neither disagrees or agrees, agree and strongly agree. Questionnaire was divided into three sections. Questions in the first section collected the socio-demographic data, so as to identify relationship between these variables.

The second section reflected the intention to change job among nurses. What as intention to change job? And to clarify the concept, this variable was delineated in to two dimensions.

Intention to change job was differentiated into intention to change working sector and intention to leave nursing profession. The change of working in intention to change working sector was referring to a change of working environment, such as, internal transfer within the hospital, transfer to other hospital, change to health department, change to old age home, work in private general practitioner clinic or out-patient department but still practicing nursing. The intention to leave the nursing profession referred to changing the nature of their jobs. They would quit nursing and work in other occupations, such as, medical product sales or 
correctional service officer or others. The job natures of these occupations were not related to nursing practice.

Intention to change job was also understood in two directions. The first was desired to change jobs, which was conceptually defined as nurse's inclination to change jobs. They were thinking of quitting, if they had the opportunity to meet other alternatives, they would accept the alternative. The second, nurses action tendency to leave, was regarded as respondents action tendency to leave which referred to respondents who were actively searching for alternative work and thus creating the opportunity of quitting.

Four types of intention to change jobs included:

1. Desire to change working setting. (DCWS)

2. Desire to leave nursing profession. (DLNP)

3. Action tendency to change working setting. (ACWS)

4. Action tendency to leave nursing profession .( ALNP)

This section considered nurses expectations of their future satisfaction of the work values and career plans and evaluated the relationships between job satisfaction, thinking of quitting, intention to search, probability of finding an acceptable alternative, intention of quitting, and actual attrition.

In the third section, the questions were to measure the job satisfaction level of nurses. Corresponding to Pasternak's finding in 1988, job nature, patient, promotional opportunity, education and training were related to motivation factors of Herzberg or the two upper levels of Maslow's hierarchy of needs. In addition to income, supervision, colleagues, and social prestige workload and shift duty were associated with the hygiene factors or three lower levels of needs.

The ten dimensions of nurse job satisfaction included were:

1. Job Nature. (SATNUR)

2. Income. (SATINC)

3. Social Prestige of Nurses. (SATPRE)

4. Supervisor. (SATSUP)

5. Colloquy. (SATCAL)

6. Patient. (SATPAT)

7. Promotion Opportunity. (SATEDU) 
8. Education and Training. (SATEDU)

9. Workload. (SATLOA)

10. Shift Duty. (SATSD)

Among the ten dimensions of nurses job satisfaction. It was anticipated that the nursing profession as a whole would share satisfaction with job nature, income and social prestige of nurses. Satisfaction with supervisor, patient, colleague, promotional opportunities, education and training, workload, and shift duty were considered as related to particular of hospital in the context of Kuwait.

\section{HYPOTHESIS}

1. Dissatisfaction with the job nature, income and social prestige of nurses would result in intention of withdrawing from nursing and/or the nursing profession.

2. Dissatisfaction with the supervisor, patient, colleague, promotional opportunity, education and training workload and shift duty would elicit intention of leaving the present sector.

\section{EXPLORE VARIABLES}

\section{Desire to leave nursing profession. ( DLNP )}

Desire to leave nursing was defined as nurses propensity to give up nursing if they had the opportunity to do so. Three-item scale was employed to measure this attitudinal construct on 5-point Likert scale.

- I would quit nursing for another occupation paying a slightly lower salary. (DLLOWERS)

- I would quit nursing for another occupation paying an equal salary.(DLEQUALS)

- I would quit nursing for another occupation paying a higher salary.(DLHIGHERS)

\section{Desire to change working sector. ( DCWS )}

Desire to change work sector was define as nurses inclination to change working sector if they have the opportunity to do so. A three-item scale was employed to measure this attitudinal construct on 5-point Likert scale.

- If offered employment in another health care sector offers me a job, I shall accept even though the opportunity of promotion may be slightly lower than in my present one. ( DCLOWERP ) 
- If offered a similar level position in anther health care sector, I shall accept it. ( DCEQUALPOSITION)

- If offered employment with higher opportunity of promotion in other health care sector, I shall accept it. (DCHIGHERP)

\section{Action tendency to leave nursing profession. ( ALNP)}

Investigate Nurses' intentions to find jobs in other occupational sectors. That means the nurses would give up nursing practice. To measure this construct, the respondents had to indicate their degree of agreement on the statement on 5-point scale.

- I intend to actively seek employment in another field in the near future. ( ALNUR )

\section{Action tendency to change work sector. (ACWS )}

This was defined as nurse's intentions to fine a nursing job in another health care sector 5-point Likert scale was employed to measure this attitude.

- In the near future, I shall actively seek employment to in another health care sector. . ( ACWS )

\section{INDEPENDENT VARIABLES}

Job Satisfaction was the independent variable. The following items were used to measure nurses' extent of job satisfaction. Each item was measured on a 5-point Likert scale.

\section{Satisfaction with job nature (SATJNUR)}

- I always enjoy providing nursing care.

- I get feelings of worthiness and accomplishment from my work.

- I always think of my job as challenging.

- I always think of my job as Varied.

- I can to endure the pressure of the nursing profession.

\section{Satisfaction with income (SATINC)}

- I am satisfied with my present income.

- Compared with other occupations nursing is fairly well paid.

- I am satisfied with the annual salary increment.

- Income from nursing provides me with a comfortable life style. 
3. Satisfaction with social prestige of nurse ( SATPRE )

- In Kuwait, nurses are respected.

- I am proud of being a nurse

- In Kuwait, the social status of nurse is quite high.

4. Satisfaction with supervisor (SATSUP)

- I always receive support and guidance from my supervisors.

- I always receive respect and fair treatment from my supervisors.

- When my supervisors criticize a nurse, their manners are appropriate.

- The opinions of nurses are always taken seriously by my supervisors.

- My supervisors always respect the autonomy of nurses.

5. Satisfaction with colleague (SATCOL)

- Most of my colleagues are willing to accept the opinions of others.

- Most of my colleagues seldom intervene in my job unnecessarily.

- When my colleagues pass an opinion on my job, their manners are appropriate.

- I feel that I am part of the team.

- I can get help from my colleagues.

6. Satisfaction with patient (SATPAT)

- My patients value the efforts imposed my works.

- Most of my patients respect the nurse.

7. Satisfaction with promotional opportunity (SATPRO)

- In the foreseeable future, I expect to have a promotion opportunity in my present hospital.

- If a promotion opportunity is available, my chance is better than those of my competitors are.

- There are sufficient opportunities for the promotion of nurses.

8. Satisfaction with education and training (SATEDU)

- I have adequate nursing training in dealing with patient care.

- I think my nursing training is of adequate professional standard.

- I have time off to attend courses.

- I can get sponsorship to attend courses. 


\section{Satisfaction with workload ( SATLOA)}

- I have enough time for patient care.

- The overall staffing level is appropriate.

- I spend limited amount of time on non-nursing.

- My works matches my job description.

\section{Satisfaction with shift duty (SATSD )}

- I like shift duty.

- Shift duty allows me enough time to handle my personal affairs.

- Shift duty does not affect my social life.

\section{Pilot Study}

A pilot study was done on the staff nurses in Al-Razi Hospital in Kuwait in January 2019. The participants in the pilot study were not included in the core of the study. They were requested to complete the pre-test-and re-test with a time within two weeks. The time expender of the completion of the questionnaire was 15 minutes. Modifications of the questionnaire were made some wording arrangement of presentation after the pilot study.

The correct validity of the instrument has been established after the validation. The overall items analysis of test and re-test reliability was 0.81 and level of significant of $p<0.01$ was obtained.

\section{Presentation of Data Data Processing}

In order to make the results of the survey more valid and reliable, data processing flows were conducted. The data processing flows include:

1. Deciding whether to use the data collection instrument for analysis.

2. Editing.

3. Coding.

4. Keypunching. On the computer entering and verifying readable from.

5. Converting the data deck into a computer readable form.

6. Cleaning the data set.

7. Generating new variables as necessary.

8. Weighting the data in accordance with the sampling plan and results.

9. Storing the data set on desk for further analysis. 
After the collection of questionnaire, the data had been coded according to the coding manual, a computer software package "SPSS" program. Was used to keypunch the data. Hence, a data set was created and several statistical programmers were written in order to clean the incorrect records. After the process of cleaning the data file set, no record was deleted from the data set as a result of serious data error. As a result, all 311 cases were retained from the survey and then were used for further study.

\section{DATA ANALYSIS TECHNIQUES \\ Univariate data Analysis}

In order to estimate the preliminary results, univariate data analysis was applied for every question in the questionnaire. The analyses were mostly done for descriptive purposes. The objective of descriptive statistics was to provide summary measures of the data contained in all the elements of a sample. In doing so, measures of central tendency and dispersion were used. Therefore, frequency and means plots were used to create descriptive charts such as tables, pie chart, bar charts and so on.

Some hypothesis testing of university data were also applied in the analysis, T-test was used instead of the Z-test because the population variance of the variables was unknown.

\section{Bivariate Data Analysis}

Bivariate data analysis was used to see whether there was any correlation between two variables. Two-Way contingency Tables, which were the matrix display of the categories about two variables, containing frequency count of the number of the number of object on each bivariate category, were used to assess the relationship between two variables. Besides, concerning hypothesis testing, Chi-square test as well as T-test was used to monitor if there was a relationship between them. The Chisquare tests were applied on two nominal variables while the t-tests were applied on two interval variables.

\section{Multivariate Data Analysis}

Basically, the multivariate analysis divided into interdependences and dependence procedures. The fundamental differentiating aspect between the two procedures was whether one or more variables have been designated as dependent on other variables. As one or more 
variables in the survey were designated as being predicted by set of independent variables, dependence methods were applied. Multiple regressions and the analysis of variance were adopted in the survey.

While applying the multiple. It required that both the dependent and independent variables should be interval scaled. Also, it assumed that the underlying relationship was linear, in spite of the fact that data transformations could overcome this latter problem. Finally, as the sample size should be large enough to give many observations for each independent variable, multiple regressions could be applied properly.

In this study, the dependent variables like DLNP, ALNP, DCWS and ACWS could be studied as well as they could be transformed into interval scale. Besides, for the independent variables like SATNUR, SATINC, SATPRE, SATSUP, SATCOL, SATPAT, SATPRO, SATEDU, SATLOA and SATSD could also be studied because they might roughly be regarded as a nominal scale.

\section{Demographic Sample Characteristics:}

The total number of questionnaire which distributed was 311 questionnaire, $78.5 \%$ of the respondents were females $(N=245)$.

The age distribution of the respondents showed that $26.2 \%$ were aged between $26-30$ years, while $21.9 \%$ represents the age group $31-$ 35 years old. Figure (1) shows the age distribution of the respondents.

Figure (1) Age distribution of the sample

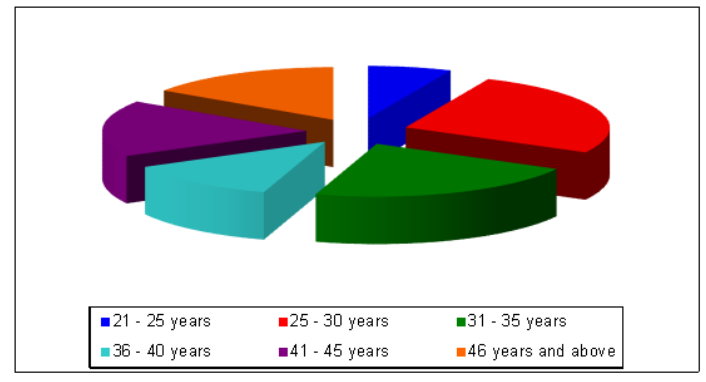


Table (1) shows the marital status of the respondents by their qualifications.

Table (1) Marital status by qualification of the sample

\begin{tabular}{|l|c|c|c|c|c|c|c|c|}
\hline & \multicolumn{2}{|c|}{ General nursing } & \multicolumn{2}{l|}{ Psychiatric Nurse } & Others & \multicolumn{2}{l|}{ Total } \\
\cline { 2 - 9 } & Count & Percent & Count & Percent & Count & Percent & Count & Percent \\
\hline Single & 39 & $18.5 \%$ & 4 & $18.2 \%$ & 2 & $18.2 \%$ & 56 & $18.5 \%$ \\
\hline Married & 167 & $79.1 \%$ & 18 & $81.8 \%$ & 9 & $81.8 \%$ & 239 & $79.1 \%$ \\
\hline Divorced & 5 & $2.4 \%$ & - & - & - & - & 5 & $2.4 \%$ \\
\hline Total & 211 & $100 \%$ & 22 & $100 \%$ & 11 & $100 \%$ & 22 & $100 \%$ \\
\hline
\end{tabular}

The distribution of the highest academic qualification of the sample is shown in the Figure (2). Most of the sample has Diploma (49\%) or Bachelor (35\%) degree.

Figure (2) Academic qualification of the sample

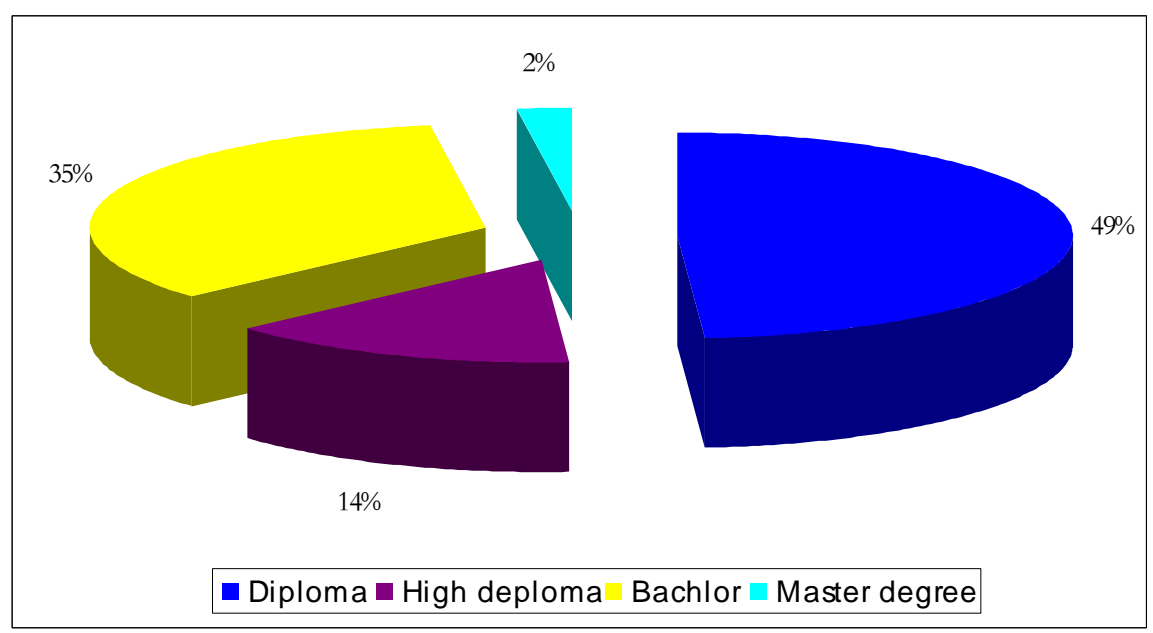

Figure (3) shows the current position of the respondents. Most of the respondents are working as staff nurse.

Figure (3) Current position of the study's respondents 


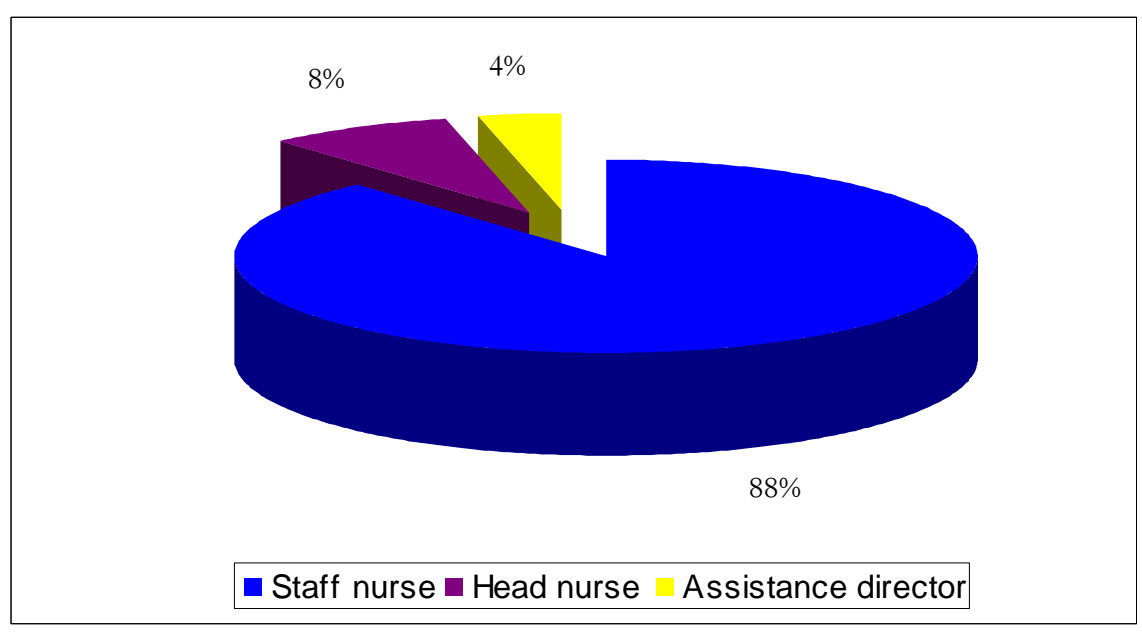

Figures (4) illustrates years of experience of the sample. It is shown that $31.7 \%$ of the data had 16 years and more of experience, while 17.8 $\%$ of the sample had $11-15$ years of experience.

Figure (4) Level of experience for the sample

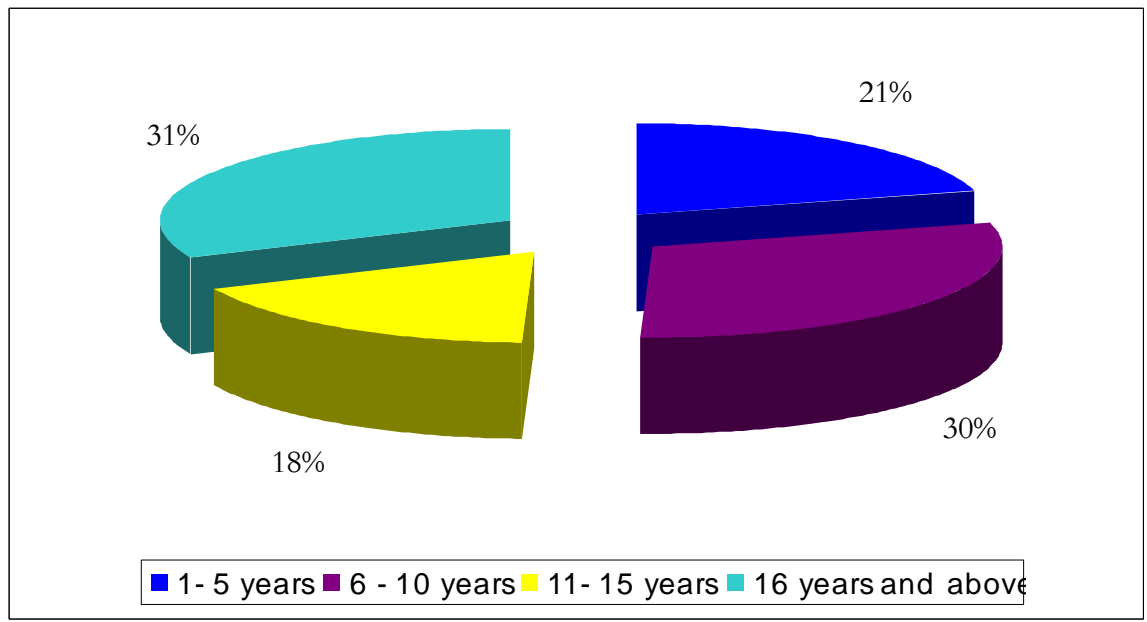

Finally, as for the current area of practice $19.1 \%$ of the respondents work in the Orthopedic unit, while only $1.4 \%$ of the respondents work in the Oncology unit, the graph below shows the distribution of the current area of practice: 
(Graph No (6) illustrates Functional Specialization Variable of the sample)

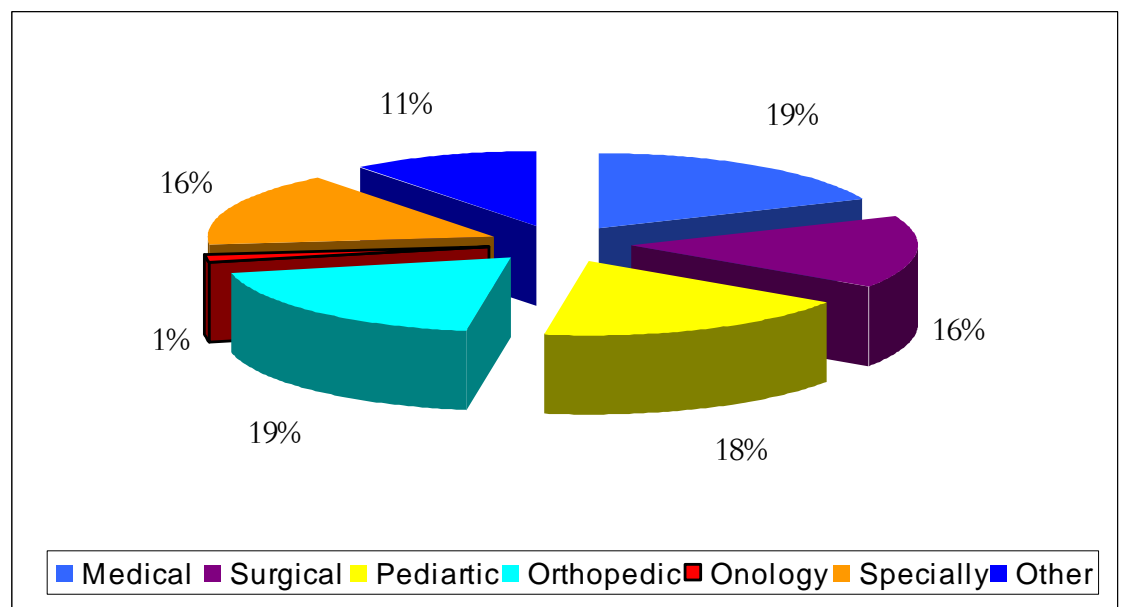

\section{Analysis of the Dependent Variables}

Reliability analysis allows studying the properties of measurement scales and the items that make them up. The Reliability Analysis procedure calculates a number of commonly used measures of scale reliability and also provides information about the relationships between individual items in the scale.

The variable " desire to leave nursing profession " is indicating that the sample are disagree with leaving the nursing profession and almost $7 \%$ of the respondents agree with leaving the nurse profession. CRONBACH ALPHA $=0.6538$.

The variable "desire to change work sector "shows that the sample are disagree with and almost $17 \%$ of the respondents agree with it .CRONBACH ALPHA $=0.6391$.

The variable "Action tendency to leave nursing profession " $57 \%$ of the respondents are disagree with it and only $17 \%$ of the sample agree on "Action tendency to leave nursing profession ".CRONBACH ALPHA = 0.5267 .

The variable " Action tendency to change nursing profession " $47 \%$ of the respondents are disagree with it and only $23 \%$ of the sample agree on "Action tendency to change nursing profession ".CRONBACH ALPHA = 0.5734 . 
The frequency distribution of the score DLNP was as follows : $7.4 \%$ of the sample are agree to leave the nursing profession however, more than $70 \%$ of them were disagree to leave the nursing profession . Table (2) shows percentage of the items related to "desire to leave nursing profession " variable.

Table (2) Sample response rates for desire to leave nursing profession variable

\begin{tabular}{|c|c|c|c|}
\hline Item & Satisfaction & Neutral & Dissatisfaction \\
\hline $\begin{array}{c}\text { I would quit nursing for another } \\
\text { occupation paying a slightly lower salary. }\end{array}$ & $4.6 \%$ & $3.5 \%$ & $91.9 \%$ \\
\hline $\begin{array}{c}\text { I would quit nursing for another } \\
\text { occupation paying an equal salary. }\end{array}$ & $13.4 \%$ & $9.8 \%$ & $76.9 \%$ \\
\hline $\begin{array}{c}\text { I would quit nursing for another } \\
\text { occupation paying a higher salary. }\end{array}$ & $36.1 \%$ & $13.4 \%$ & $50.5 \%$ \\
\hline
\end{tabular}

Referring to the desire to change work sector variable, the frequency distribution was as follows : $39.7 \%$ of the sample were disagreed, while $17.5 \%$ of them were agreed. Table (3) shows percentages of the items related with this variable.

Table (3) Sample response rates for desire to change work sector variable

\begin{tabular}{|c|c|c|c|}
\hline Item & Satisfaction & Neutral & Dissatisfaction \\
\hline $\begin{array}{c}\text { If offered employment in } \\
\text { another health care sector } \\
\text { offers me a job, I shall accept } \\
\text { even though the opportunity of } \\
\text { promotion may by slightly } \\
\text { lower than in my present one. }\end{array}$ & $10.0 \%$ & $14.9 \%$ & $76.1 \%$ \\
\hline $\begin{array}{c}\text { If offered a similar level position } \\
\text { in another health care sector, I } \\
\text { shall accept it. }\end{array}$ & $26.9 \%$ & $21.0 \%$ & $52.1 \%$ \\
\hline $\begin{array}{c}\text { If offered employment with } \\
\text { higher opportunity of } \\
\text { promotion in other health care } \\
\text { sector, I shall accept it. }\end{array}$ & $61.6 \%$ & $17.0 \%$ & $21.4 \%$ \\
\hline
\end{tabular}


As for action tendency to leave nursing profession variable (as operationalized by: I intend to actively seek employment in another field in the near future item), it was found that $18.3 \%$ of the sample were agreed while $58.5 \%$ of them disagreed. With regard to action tendency to change work sector variable (as operationalized by: In the near future , I shall actively seek employment to another health care sector item), it was found that $24.4 \%$ of the sample were agreed however, $48.4 \%$ of the sample disagreed.

\section{Analysis of the Independent Variables}

Ten factors are measuring the extent of job satisfaction of nurses. The study hypothesized that the extent of the satisfaction with job nature, income, and social prestige of nurses was related to the nursing profession while the satisfaction with their supervisor, patient, colleague, promotion opportunity, education, training, workload and finally shift duty were considered as related to the particular situation of health care sector.

Each item was measured on a 5-point Likert scale measuring from "5" (strongly agree); to "1" (strongly disagree). In order to understand whether the independent variables were internally consistent and reliable, Cronbach's alpha coefficient was calculated. Table (4) shows Cronbach's alpha values, mean and standard deviation for each independent variable.

Table (4) Cronbach's alpha values, means, and SDs for independent variables

\begin{tabular}{|l|l|l|l|}
\hline Factor & Alpha & Mean & S.D \\
\hline Job nature & 0.6405 & 4.08 & 0.69 \\
\hline Income & 0.7551 & 2.98 & 0.92 \\
\hline Social prestige of nurse & 0.4615 & 3.00 & 0.80 \\
\hline Supervisor & 0.8621 & 3.44 & 0.85 \\
\hline Colleague & 0.6517 & 3.77 & 0.57 \\
\hline Patient & 0.5693 & 2.91 & 0.92 \\
\hline Promotional opportunity & 0.5690 & 2.87 & 0.81 \\
\hline Education and training & 0.5236 & 3.35 & 0.72 \\
\hline Workload & 0.4938 & 3.27 & 0.73 \\
\hline Work duty & 0.8097 & 3.89 & 0.89 \\
\hline
\end{tabular}


Table (4) reveals that the target respondents were most satisfied with the job nature, since its mean was the highest among the ten variables. However, the Income is the most unsatisfied factor among the ten factors since its mean was the lowest among them.

\section{Correlation analysis among variables}

Correlational analysis is used to study the hypotheses that dissatisfaction with the nature of the job, income and social prestige of nurses would result in the intention of quitting from nursing profession. and that dissatisfaction with the supervisor, patient, colleague, promotion opportunity, education and training, workload, and shift duty would elicit the intention of leaving the present health care sector, Therefore, for model one it involves the independent variables DLPN, and ALNP together with the independent variables SATNUR, SATINC, and SATPRE. Table (5) illustrates correlation coefficients among the study's variables.

Table (5) correlation coefficients among the study's variables

\begin{tabular}{|l|l|l|l|l|}
\hline & DLNP & ALNP & SATNUR & SATINC \\
\hline ALNP & $0.414 * *$ & & & \\
\hline SATNUR & $-0.304^{* *}$ & -0.082 & & \\
\hline SATINC & $-0.214 * *$ & $-0.154 * *$ & $0.124^{*} *$ & \\
\hline SATPRE & $-0.224 * *$ & $-0.186 * *$ & $0.237^{* *}$ & $0.506 * *$ \\
\hline
\end{tabular}

** Sig. at 0.01 level * Sig. at 0.05 level

As shown in Table (5) there is a negative correlation between the dependent variables and the three independent variables since the correlation coefficient between then are negative and significant. This means that the more satisfaction of the nurse the less is the desire to leave the profession, and will be no action to leave nursing profession.

In addition, correlations among the dependent variables: DCWS and ACWS and the independent variables: SATSUP, SATCOL, SATPAT, SATPRO, SATEDU, SATLOA, and SATSD, are shown in Table (6). 
Table (6) correlation coefficients among dependent and independent

\begin{tabular}{|c|c|c|}
\multicolumn{3}{|c|}{ variables } \\
\hline & DCWS & ACWS \\
\hline ACWS & $.546^{* *}$ & \\
\hline SATSUP & $-.215^{* *}$ & $-.214^{* *}$ \\
\hline SATCOL & -.129 & -.064 \\
\hline SATPAT & -.044 & -.062 \\
\hline SATPRO & .072 & .133 \\
\hline SATEDU & -.053 & -.031 \\
\hline SATLOA & -.096 & -.068 \\
\hline SATSD & -.191 & -.110 \\
\hline
\end{tabular}

As shown in Table (6) there were a weak correlations among the independent and the dependent variables; since the correlation coefficient is not significance with most variables (except for ACWS with DCWS, and SATSUP with DCWS and ACWS), and the other variables have weak and negative correlations with the dependent variables. Hence it indicate that the higher the job satisfaction of a given nurse the lower the nurses intention to change the working sector.

regression analyses.

Multiple linear Regression is used to understand the relation between job satisfaction and intention to leave nursing profession, as well as the relationship between job satisfaction and intention to change working sectors. In this analysis, a predictor variable would enter the regression model with the acceptable level of significance and the coefficient of the determination (R-square) would be as large as possible. Then, another predictor variable would be entered to the model in the same manner while the acceptable level of significance (0.05) had not just been violated. Considered relevant variables were entered so that the method itself identified the significant predictor and extracted decreasingly important factors.

Job satisfaction and intention to leave nursing profession

Table (7) summarize results for the regression analysis for job satisfaction variables as the independent variables and intention to leave nursing profession variables as dependent variables. Although the models were significant, the total explanatory power for both DLNP and ALNP 
were not high. The three independent variables explained $11.9 \%$ of the DLNP variance, and only $3.1 \%$ of the ANLP variance.

Table (7) summarize results for the regression analysis for Job satisfaction and intention to leave nursing profession

\begin{tabular}{|c|c|c|}
\hline \multicolumn{3}{|c|}{ Beta coefficient } \\
\hline SATNUR & DLNP & ALNP \\
\hline SATINC & $-.432 * *$ & -.044 \\
\hline SATPRE & $-.185^{* *}$ & -.080 \\
\hline Multiple R & -.093 & $-.305^{* *}$ \\
\hline R - Square & 0.353 & 0.186 \\
\hline
\end{tabular}

The Beta coefficient revealed that nurse's satisfaction with the job nature was the most powerful predictor of their desire to leave nursing profession (DLNP). Satisfaction with income was the next one; however, the explanatory power of satisfaction with social prestige was found to be trivial and insignificant.

On the other hand, satisfaction with social prestige for nurse was the most powerful predictor of nurse action tendency to leave the profession, and both satisfaction variable (SATNUR and SATINC) were both trivial and insignificant.

So we conclude that action tendency to leave nursing profession is effected by the satisfaction of social prestige, and the satisfaction of job nature and the satisfaction of the income are effect in the decision of leaving the nursing profession.

Job satisfaction and intention to change nursing profession

Table (8) summarize results for the regression analysis for job satisfaction variables as the independent variables and intention to change nursing profession variables as dependent variables. 
Table (8) summarize results for the regression analysis for Job satisfaction and intention to change nursing profession

\begin{tabular}{|c|c|c|}
\hline \multicolumn{3}{|c|}{ The Beta coefficient } \\
\hline & DCWS & ACWS \\
\hline SATSUP & $-.216^{* *}$ & $-.386^{* *}$ \\
\hline SATCOL & -.042 & -.014 \\
\hline SATPAT & -.005 & -.058 \\
\hline SATPRO & $.148^{* *}$ & $.308^{* *}$ \\
\hline SATEDU & .008 & -.047 \\
\hline SATLOA & .011 & -.018 \\
\hline SATSD & $-.134^{* *}$ & -.052 \\
\hline Multiple R & 0.278 & 0.287 \\
\hline R - Square & .068 & .076 \\
\hline
\end{tabular}

As shown in Table (8), the total explanatory power for DCWS is $6.8 \%$ and for ACWS was $7.6 \%$. However, the Beta coefficient revealed that nurses satisfaction with satisfaction with supervisor SATSUP the most powerful predictor on the desire to change nurse working sector, then comes the variable satisfaction with shift duty SATSD, and finally the variable satisfaction with promotional opportunity SATPRO is the lowest variable that effect on the DCWS, while the other variables were insignificant with the dependent variable DCWS.

On the other hand, the Beta coefficient shows that the variable satisfaction with supervisor SATSUP is the most powerful variable among the seven independent variables that effect on ACWS; and the next variable was satisfaction with promotional opportunity, and the rest of the variables were insignificance with the dependent variable Action tendency to change work sector.

\section{Conclusion}

The nursing profession, health care system and Kuwait are facing lots of changes in this period. During this period, Kuwait needs large effective and efficient working forces of nurses to maintain the health care services of the community. However, nursing is confronted with the problems of recruitment from an apparently dwindling pool of qualified staff and apparently fewer students entering nurses training. The recruitment of nurses cannot replace the loss, and as a result, the shortage of nurses is aggregated. The loss of nurses results in the loss of knowledge. The consequence will be a reduction in the quality of patient care. On the 
other hand, it is expensive to retain, recruit, and train nurses. Studies on job satisfaction and turnover become increasingly important if the provision of care is to be maintained and the hospital budgets are managed more efficiently.

nursing profession and almost $38 \%$ of the sample are disagree inn changing work sector. On the other hand $57 \%$ of the respondents are disagree with action tendency to leave nursing profession and $47 \%$ of the respondents are disagree with action tendency to change nursing profession. Also the study shows hat the target respondents were most satisfied with the job nature. However, the promotional opportunity is the most unsatisfied factors among the ten factors.

From the analysis of the correlation among variables it shows that there is a negative relation between the dependent variables and the their independent variables and also these are significant which means that the more satisfaction of the independent variables the less is the desire to leave the profession and it will be no action to leave nursing profession. Also from the finding we can conclude is that the higher the job satisfaction of nurse the lower the nurse intention to change the work sector.

Also the study reveals that nurse satisfaction with job nature was the most powerful predictor of their desire to leave nursing profession. On the other hand, satisfaction with social prestige of the nurse was the most powerful predicator of nurse action tendency to leave the profession.

Finally, In job satisfaction and intention to change nursing profession that the nurses satisfaction with satisfaction with supervisor is the most powerful predictor on the desire to change work sector. 


\section{REFERENCES}

- Aiken et al. (2013) Aiken LH, Sloane DM, Bruyneel L, Van DHK, Sermeus W. Nurses' reports of working conditions and hospital quality of care in 12 countries in Europe. International Journal of Nursing Studies.

- Akgöz et al. (2005) Akgöz S, Özçakir A, ismet K, Tombul ÖBBK, Altinsoy SHY, sivrioğlu Y. The professional satisfaction of nurses employing in health, application and research center (suam) of Uludağ University. Turkiye Klinikleri Journal of Medical Ethics, Law and History. 2005;13(2):86-96.[Google Scholar]

- Al-Awadhi A. (1987). The Arabic Role in Word Health Organization. The Arabic Center for Documentation and Health printing.1987.

- Al-Bustan M. ( 1987). The Kuwait's Health and The Role of Health Education. pp 17-27.

- American Nurses ' Association.( 1991). " Staff Shortage Hurting' 'Nursing American Journal of Nursing, 91:1:85-90.

- American Psychological Association. (2001) Publication Manual of the American Psychological Association $\left(5^{\text {th }}\right.$ Edition). Washington. DC. Author.

- Applebaum et al. (2010) Applebaum D, Fowler S, Fiedler N, Osinubi $\mathrm{O}$, Robson $\mathrm{M}$. The impact of environmental factors on nursing stress, job satisfaction, and turnover intention. The Journal of Nursing Administration. 2010;40(7-8):323-328

- Asegid, Belachew \& Yimam (2014) Asegid A, Belachew T, Yimam E. Factors influencing job satisfaction and anticipated turnover among nurses in sidama zone public health facilities, south Ethiopia. Nursing Research and Practice.

- Beecroft, Dorey \& Wenten (2008) Beecroft PC, Dorey F, Wenten M. Turnover intention in new graduate nurses: a multivariate analysis. Journal of Advanced Nursing. 2008;

- Borkowski et al. (2007) Borkowski N, Amann R, Song S-H, Weiss C. Nurses' intent to leave the profession: issues related to gender, ethnicity, and educational level. Health Care Management Review. 2007;32(2) 
- Carey, R., Johnson, H., and Kerman, F. (1997) Improvement in employee morale Linked to a variety of agents. Hospitals 50(19): 8588.

- Cavanagh, S. J. (1992) Job Satisfaction Oof nursing staff Work in Hospital, Journal of Advance Nursing, 17,pp. 704-711.

- Chan et al. (2009) Chan MF, Luk AL, Leong SM, Yeung SM, Van IK. Factors influencing Macao nurses' intention to leave current employment. Journal of Clinical Nursing. 2009

- Cowin et al. (2008) Cowin LS, Johnson M, Craven RG, Marsh HW. Causal modeling of self-concept, job satisfaction, and retention of nurses. International Journal of Nursing Studies. 2008;45(10):14491459.

- Cronin-stubs, D. (1977) Job satisfaction and dissatisfaction among new graduate staff nurses. Journal of Nursing Administration 7(10): 44-49.

- Delobelle et al. (2011) Delobelle P, Rawlinson JL, Ntuli S, Malatsi I, Decock R, Depoorter AM. Job satisfaction and turnover intent of primary healthcare nurses in rural South Africa: a questionnaire survey. Journal of Advanced Nursing. 2011;67(2):371-383.

- El-Jardali et al. (2009) El-Jardali F, Dimassi H, Dumit N, Jamal D, Mouro G. A national cross-sectional study on nurses' intent to leave and job satisfaction in Lebanon: implications for policy and practice. BMC Nursing. 2009;8(1):3.

- Erdem et al. (2008) Erdem R, Rahman S, Avcı L, Göktaş B, Şenoğlu B, Firat G. Investigating Job Satisfaction and Burnout Levels of the Persons Working for the Hospitals at City Center of Elaziğ, Turke. Journal of Applied Science Research. 2008;4(2):188-201.

- Fitzpatrick et al. (1988) Fitzpatrick R, Davey C, Buxton MJ, Jones DR. Evaluating patient-based outcome measures for use in clinical trials. Health Technology Assessment. 1988;2:1-7

- Flinkman et al. (2008) Flinkman $M$, Laine $M$, Leino-Kilpi $H$, Hasselhorn H-M, Salanterä S. Explaining young registered Finnish nurses' intention to leave the profession: a questionnaire survey. International Journal of Nursing Studies. 2008;45(5):727-739. 
- Flinkman, Isopahkala-Bouret \& Salanterä (2013) Flinkman M, Isopahkala-Bouret U, Salanterä S. Young registered nurses' intention to leave the profession and professional turnover in early career: a qualitative case study. ISRN Nursing.

- Ginzberg, E., Patray, J., Ostow, M., and Brann, E. (2000) Nurse Discontent, the search for realistic solutions. Journal Of Nursing Administration 12(11): 7-11.

- Gök \& Kocaman (2011) Gök AU, Kocaman G. Reasons for leaving nursing: a study among Turkish nurses. Contemporary Nurse. 2011;39(1):65-74. doi: 10.5172/conu.

- Gormley (2011) Gormley DK. Are we on the same page? Staff nurse and manager perceptions of work environment, quality of care and anticipated nurse turnover. Journal of Nursing Management.

- Hakeem, et. (1999) The Development of a Nurses Job Satisfaction Measure in Kuwait, Kuwait Medical Journal. Feb Issue, pp. 23-26

- Hale, C. (1996) Measuring Job Satisfaction, nursing times, 82(5), pp. 43-46.

- Han \& Jekel (2011) Han GH, Jekel M. The mediating role of job satisfaction between leader-member exchange and turnover intentions. Journal of Nursing Management.

- Hayes, Bonner \& Pryor (2010) Hayes B, Bonner A, Pryor J. Factors contributing to nurse job satisfaction in the acute hospital setting: a review of recent literature. Journal of Nursing Management.

- Heinen et al. (2013) Heinen MM, Van Achterberg T, Schwendimann R, Zander B, Matthews A, Kózka M, Ball J. Nurses' intention to leave their profession: a cross sectional observational study in 10 European countries. International Journal of Nursing Studies.

- Herzberg, F . (1968) Work and the Nature of Nab, London : Staples Press.

- Herzberg, F ., Mausner, B. \& Snyderman, B. (1959) The Motivation to Work, New York: Wiley.

- Herzberg, F.(1966) Work and the Nature of man. Cleveland: World Publishing. 
- Hosmer Jr, Lemeshow \& Sturdivant (2013) Hosmer DW, Jr, Lemeshow S, Sturdivant RX. Applied logistic regression. Vol. 398. Hoboken: John Wiley \& Sons; 2013.

- Hurka, S. (1974) Organization environment and work satisfaction. Dimensions in Health Service 51(1):41-43.

- Hyrkas \& Morton (2013) Hyrkas K, Morton JL. International perspectives on retention, stress and burnout. Journal of Nursing Management.

- Institute of Medicine.( 1993) Nursing and education: Public Policies and Private Actions. Washington, Dc: National Academy Press.

- Jolma, D. (1990) Relationships between Nursing Workload and Turnover. Nursing Economics 8(2):110-113.

- Jones, C.B.( 1990) "Staff Nurse Turnover Costs: Part I , A Conceptual Model of Nursing Administration, a,20:4:18-23.

- Kacel, Miller \& Norris (2005) Kacel B, Miller M, Norris D. Measurement of nurse practitioner job satisfaction in a Midwestern state. Journal of the American Academy of Nurse Practitioners.

- Kaldenberg Do, Regrut Ba.( 1999) Do Satisfied Patients Depend on Satisfied Employees? Or do satisfied employees Depend on satisfied patient? The Satisfaction Report Newsletter. Volume 3. South Bend, Ind: Press, Ganey Associates Inc.

- Kaplan, R. (1984) person-Environment Fit: Past, Present, and Future. III.Scott: Foresman \&Co..

- Katz, R., and Van Maanen, J. (1977) the Loci of work Satisfaction: Job interaction and policy. Human relations 30:468-486.

- Kuwait Ministry of Public Health (1997). Health Kuwait. Kuwait, Health \& Vital Statistics Department of statistics \& Medical Records, pp. 17- 27.

- Kuwait Ministry of Public Health (2001). Health Kuwait.Kuwait, Health \& Vital Statistics Department of statistics \& Medical Records, pp. 1- 50.

- Leiter, Price \& Spence Laschinger (2010) Leiter MP, Price SL, Spence Laschinger HK. Generational differences in distress, attitudes and incivility among nurses. Journal of Nursing Management. 
- Likert, R., and Likert, J. (1976) New ways of managing conflict. New York: McGraw-Hill.

- Lisa Hope Pelled and Katherine R. Xin, Down and Out. (1999). An Investigation of the Relationship between Mood and Employee withdrawal Behavior, Journal of Management, Vol. 25. 6 PP. 975895.

- Liu et al. (2012) Liu C, Zhang L, Ye W, Zhu J, Cao J, Lu X, Li F. Job satisfaction and intention to leave: a questionnaire survey of hospital nurses in Shanghai of China. Journal of Clinical Nursing.

- Locke, E. A. (1976) the nature and Consequences of job Satisfaction, in M.D. Dunnette (Ed) Handbook of industrial and Organizational Psychology, Chicago: Rand-Mcnally.

- Loo \& Beh (2012) Loo LH, Beh LS. Job stress and coping mechanism among nursing staff in public health services. International Journal of Academic Research in Business and Social Sciences.

- Lu et al. (2012) Lu H, Barriball KL, Zhang X, While AE. Job satisfaction among hospital nurses revisited: a systematic review. International Journal of Nursing Studies.

- Lukas, M.(1991) Management Style and Staff Nurse Job Satisfaction. Journal of Professional Nursing 7(2):119-125.

- Ma et al. (2009) Ma J-C, Lee P-H, Yang Y-C, Chang W-Y. Predicting factors related to nurses' intention to leave, job satisfaction, and perception of quality of care in acute care hospitals. Nursing Economics.

- Maslow, A.(1970) Motivation and personality. New York: Harper \& Row.

- Ma'soumah A. Ibrahim \& Ghanem Sulten. (1999) Measuring Of Mass Satisfaction towards Health Care in the State of Kuwait. Arab Journal for the Humanities. The Academic Publication Council, Kuwait University 67 (3): 114-177.

- McCarthy, Tyrrell \& Lehane (2007) McCarthy G, Tyrrell MP, Lehane E. Intention to 'leave' or 'stay' in nursing. Journal of Nursing Management.

- McClosky, J. (1974) Influence of Rewards and Incentives on Staff Nurses Turnover Rate. Nursing Research 12(3): 239-247. 
- Meeusen et al. (2011) Meeusen VC, Van Dam K, Brown-Mahoney C, Van Zundert AA, Knape HT. Understanding nurse anesthetists' intention to leave their job: how burnout and job satisfaction mediate the impact of personality and workplace characteristics. Health Care Management

- Michael Syptak , J.( 1999) ' Job Satisfaction Putting Theory Into Practice". , pp 1-12

- Moser, D., and Krikorian. (1999) Satisfaction and stress Incidents reported by hospice nurses: A pilot study. Nursing Leadership 5(4): 916.

- Mrayyan (2005) Mrayyan MT. Nurse job satisfaction and retention: comparing public to private hospitals in Jordan. Journal of Nursing Management.

- Murrells, Robinson \& Griffiths (2008) Murrells T, Robinson S, Griffiths P. Job satisfaction trends during nurses' early career. BMC Nursing.

- OECD (2013) OECD . Health at a glance 2013: OECD indicators. Paris: OECD Publishing.

- Pasternak, I.D. (1988) The effects of primary care nursing and Feelings of isolation/depersonalization of the critical care nurse, Part I: Background for the study, Nursing Management, 19(3), pp.11-18.

- Price and Mueller, loc.cit.

- Price, J. L. and C. W. Mueller.( 1995) Professional Turnover: The Case of york: Spectrum Publications.

- Prine, J., and Mueller, C.( 1995). Professional Turnover: The Case of Nurses. New York: S.P. Medical and Scientific Books.

- Sabanciogullari \& Dogan (2015) Sabanciogullari S, Dogan S. Effects of the professional identity development programme on the professional identity, job satisfaction and burnout levels of nurses: a pilot study. International Journal of Nursing Practice.

- Satisfaction Coach.(1999). Increasing Employee Satisfaction. Albuquerque.

- Seybolt, J., Pavett, C. and Walker, D.(1978) Turnover Among Nurses: It Can Be Managed. Journal of Nursing Administration 8(9):4-9.

- Seybolt, J.W.(1986) Dealing with Premature Employee turnover. Administration, 16:2:26-32. 
- Stamps, p. \& Piedmonte, E. (1986) Nurses and Work Satisfaction, Ann Arbor Mich.: Health Administration Press.

- Stewart et al. (2011) Stewart NJ, D’Arcy C, Kosteniuk J, Andrews ME, Morgan D, Forbes D, Macleod ML, Kulig JC, Pitblado JR. Moving on? Predictors of intent to leave among rural and remote RNs in Canada. The Journal of Rural Health.

- Thiry, R.( 1998) Relationship of communication satisfaction To need fulfillment among Kansas nurses. Image 11(1): 28- 29.

- Top \& Gider (2013) Top M, Gider O. Interaction of organizational commitment and job satisfaction of nurses and medical secretaries in Turkey. The International Journal of Human Resource Management.

- Torkelson \& Seed (2011) Torkelson DJ, Seed MS. Gender differences in the roles and functions of inpatient psychiatric nurses. Journal of Psychosocial Nursing.

- Tourigny, A. W. and L. Fiore.( 1998) "Nurses: Our endangered Species, Term-care Administration. 16:4:19-21.

- Van Bogaert et al. (2010) Van Bogaert P, Clarke S, Roelant E, Meulemans $\mathrm{H}$, Van de Heyning P. Impacts of unit-level nurse practice environment and burnout on nurse-reported outcomes: a multilevel modelling approach. Journal of Clinical Nursing.

- White, W., and Mitchell, T. (1979) Job enrichment vs. Social cues: A comparison and competitive test. Journal of Applied psychology 64(1):1-9.

- Wiley \& Sons, Inc. Wandelt, M., Pierce, P., and Widdowson, R. (1981) Why Nurses Leave Nursing and What Can Be Done about It. American Journal of Nursing 81 (1):72-77.

- Williamson, S. (1993) Job Satisfaction and Dissatisfaction Amongst Neonatal Nurses, Midwifery, Jun, 9(2), pp.85-95.

- Yıldız, Ayhan \& Erdoğmuş (2009) Yıldız Z, Ayhan S, Erdoğmuş Ş. The impact of nurses' motivation to work, job satisfaction, and sociodemographic characteristics on intention to quit their current job: an empirical study in Turkey. Applied Nursing Research.

- Yilmazel (2013) Yılmazel G. Mobbing, job satisfaction and affecting factors in the nurse. Turkiye Clinics Journal of Nursing Science. 
- Yurumezoglu \& Kocaman (2016) Yurumezoglu HA, Kocaman G. Predictors of nurses' intentions to leave the organization and the profession in Turkey. Journal of Nursing Management.

- Zhu et al. (2012) Zhu XW, You LM, Zheng J, Liu K, Fang JB, Hou SX, Lu MM, Lv AL, Ma WG, Wang HH, Wu ZJ, Zhang LF. Nurse staffing levels make a difference on patient outcomes: a multisite study in Chinese hospitals. Journal of Nursing Scholarship. 